\title{
Hydrogen Kinetics and Hydride Formation Effect on Zr-1Nb and Zr-1Nb-1Sn-0.1Fe Alloys for Nuclear Application
}

\author{
Leandro Martins de Oliveira ${ }^{a}$, Rodrigo Vitorino da Silva ${ }^{a}$, Dilson Silva dos Santos ${ }^{a}$,
}

\author{
Rafaella Martins Ribeiro **
}

\author{
${ }^{a}$ Programa de Engenharia Metalúrgica e de Materiais - COPPE, Universidade Federal do Rio de \\ Janeiro, PO Box 68505, 21941-972, Rio de Janeiro, RJ, Brazil
}

Received: January 17, 2017; Revised: December 06, 2017; Accepted: December 08, 2017

\begin{abstract}
The purpose of this study was to investigate the kinetics of hydrogen absorption and hydride formation and their effect on the mechanical properties in $\mathrm{Zr}-1 \mathrm{Nb}$ and $\mathrm{Zr}-1 \mathrm{Nb}-1 \mathrm{Sn}-0.1 \mathrm{Fe}$ alloys, which were thermomechanically processed and gaseously hydrided at $320^{\circ} \mathrm{C}$ under 10 bar hydrogen pressure. X-ray diffraction (XRD) confirmed the formation of $\alpha$-Zr matrix after final heat treatment. The alloys absorbed almost the same amount of hydrogen, although with different kinetics. Absorption began almost immediately in $\mathrm{Zr}-1 \mathrm{Nb}$ alloy whilst in $\mathrm{Zr}-1 \mathrm{Nb}-1 \mathrm{Sn}-0.1 \mathrm{Fe}$ hydrogen absorption started after $11 \mathrm{~h}$ besides a faster hydrogen kinetics. Results showed that tensile strengths for both alloys were nearly independent of absorbed hydrogen. Fractographic examinations indicated ductile fractures for unhydrided condition whereas quasi-cleavage features were observed for all hydrided specimens.
\end{abstract}

Keywords: hydrogen absorption kinetics, hydride, zirconium alloys, nuclear material.

\section{Introduction}

Zirconium alloys are currently being used as fuel claddings, guide tubes and grid spacer materials for nuclear applications due to their properties of low neutron absorption cross-section, both high mechanical strength and resistance to corrosion at elevated temperature and pressure ${ }^{1,2}$. New zirconium alloys such as $\mathrm{Zr}-1 \mathrm{Nb}$ and $\mathrm{Zr}-1 \mathrm{Nb}-1 \mathrm{Sn}-0.1 \mathrm{Fe}$ fulfill these requirements while providing components with extended service life. When compared to Zircaloys these materials have also shown superior properties, mainly resistance to corrosion and irradiation creep ${ }^{3}$.

All the important properties of zirconium alloys are dependent on the microstructure obtained from the manufacturing process. Several different processing routes to optimize the microstructure of fuel rods are proposed in literature ${ }^{4-6}$ with most of them indicating the recrystallized microstructure as more suitable for nuclear applications ${ }^{7,8}$. In fact, most of zirconium alloys in Pressurized Water Reactors (PWR) display a partial or fully-recrystallized microstructure?

Additionally, hydrogen interaction with zirconium alloys has long been investigated, as hydride embrittlement is the secondary life-limiting factors for fuel rods. Regular operation of a PWR nuclear reactor under 160 bar at $320^{\circ} \mathrm{C}$, can generate hydrogen by radiolysis of the coolant water, which causes zirconium oxidation and hydrogen absorption ${ }^{3}$. Furthermore, the possibility of accidents such as RIA (Reactivity initiated accident) and LOCA (Loss of coolant accident), where cladding is subjected to high-temperature oxidation after quenching because of an emergency cooling of the reactor core, can induce hydride embrittlement due to oxidation at high temperatures and consequent hydrogen absorption ${ }^{3}$.

*e-mail: rafaella@metalmat.ufrj.br
The low solubility of hydrogen in the $\alpha$-Zr phase leads to hydride formation, reducing ductility and fracture toughness, limiting the integrity of zirconium alloy components ${ }^{4,9}$. Zirconium hydride amount and orientation depend on the composition and manufacturing process, which affects the microstructure and texture of the alloy ${ }^{4,10}$. In order to avoid the risk of premature failure related to hydrogen degradation, its absorption kinetics and its effect on the mechanical properties in zirconium alloys are topics of great interest ${ }^{11}$.

$\mathrm{Zr}-\mathrm{Nb}$ based alloys have allowed to improve PWR performance, especially for higher burn-up of the fuel ${ }^{12}$ and their processing and microstructure have been extensively studied $^{4-6}$. Despite this, hydrogen kinetics interaction with the microstructure and its effect on mechanical properties under recrystallized conditions is still not fully understood.

This paper aims to study the hydrogen effect on $\mathrm{Zr}-1 \mathrm{Nb}$ and $\mathrm{Zr}-1 \mathrm{Nb}-1 \mathrm{Sn}-0.1 \mathrm{Fe}$ alloys identically processed by hot and cold rolling and heat treated to obtain a recrystallized $\alpha-\mathrm{Zr}$ matrix with $\beta-\mathrm{Nb}$ precipitates. Hydrogen interaction with the microstructure and hydride-forming conditions were determined by absorption kinetics assays, gaseous hydrogenation and X-ray diffraction. Tensile and microhardness tests were also conducted to evaluate mechanical properties and hydride embrittlement.

\section{Experimental Details}

Zirconium alloys with compositions $\mathrm{Zr}-1 \mathrm{wt} . \% \mathrm{Nb}$ (hereinafter $\mathrm{Zr}-1 \mathrm{Nb}$ ) and $\mathrm{Zr}-1 \mathrm{wt} . \% \mathrm{Nb}-1 \mathrm{wt} . \% \mathrm{Sn}-0.1 \mathrm{wt} . \% \mathrm{Fe}$ (hereinafter Zr-1Nb-1Sn-0.1Fe), were melted in a Bühler AM Vario-400 arc furnace under argon atmosphere at 200 mbar. 
Ingots were turned over and remelted five times, resulting in a $60 \mathrm{~g}$ homogenized ingot measuring $100 \mathrm{~mm}$ length, 13 $\mathrm{mm}$ width and $9.5 \mathrm{~mm}$ thickness, Figure $1(\mathrm{a})$.

The alloys were heated for 15 minutes at $850^{\circ} \mathrm{C}$ and hotrolled through $1.5 \mathrm{~mm}$ deformation passes, resulting in $83 \%$ total reduction. The obtained plates were then cold-rolled through slight deformation passes to obtain sheets about $0.95 \mathrm{~mm}$ thick and $40 \mathrm{~cm}$ long. Figure 1(b) shows the final appearance of the plates after cold rolling. Heat treatments were performed at $600^{\circ} \mathrm{C}$ for $2 \mathrm{~h}$ with air-cooling. Samples were encapsulated in glass vacuum to avoid oxidation.

Vickers microhardness tests were carried out in the cold rolled and annealed alloys in a Zwick/Roell micro durometer, Indentec $\mathrm{ZH} \mu$-MkII-M with a load of $200 \mathrm{~g}$ for $15 \mathrm{~s}$. To obtains an average value, 30 measurement were carried out on the rolling and transverse direction planes. The specimens were metallographic prepared by grinding with SiC sandpapers until 1200.

$\mathrm{X}$-ray diffraction analyses were conducted at room temperature with a Bruker D8 Discover diffractometer using $\mathrm{Cu}-\mathrm{K}_{\alpha}$ radiation to determine sample phase structures after thermomechanical process.

Measurements of hydrogen absorption kinetics were performed in the annealed samples using an automatic Sievert's type apparatus, PCT-Pro 2000 Hy Energy. To guarantee the superficial quality required for this test, samples were grinded with SiC sandpapers until 2500. The same method was used for gas hydrogenation. Tests were conducted at $320^{\circ} \mathrm{C}$ under 10 bar of $99.99 \%$ hydrogen gas atmosphere to determine the maximum amount of hydrogen that could be absorbed by the alloy at temperature close to those in which nuclear reactors operate. With this test it is possible to determine the weight percentage of hydrogen absorbed and the time that absorption occurs.

To evaluate hydride formation and the hydrogen influence on the alloys mechanical properties, gas hydrogenation was performed for $48 \mathrm{~h}$ at the same temperature and hydrogen
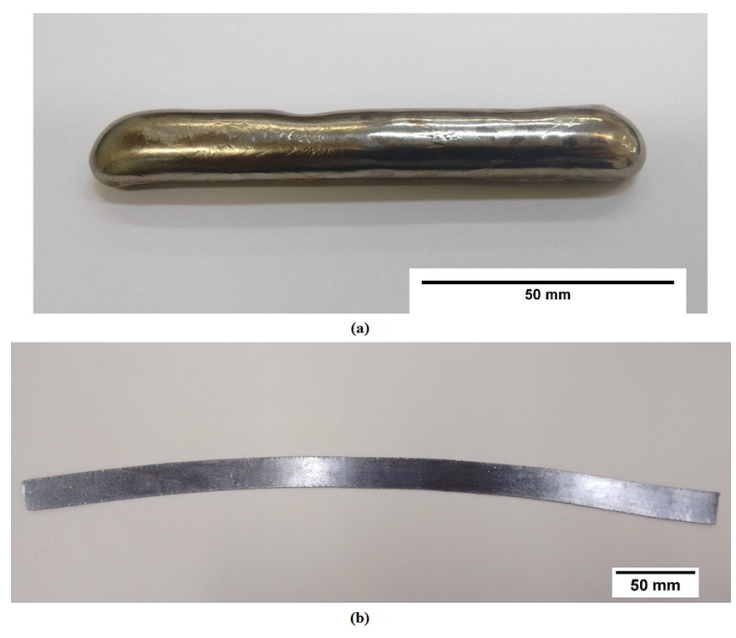

Figure 1. (a) Ingot and (b) plate obtained after rolling pressure of absorption kinetics tests. Hydride distribution and orientation after hydrogenation were observed under optical microscopy with an Olympus BX60M. Sample preparation consisted of SiC grinding with 220, 400, 600 and 1200 sandpapers then polishing with Struers cloths OPCHEM $200 \mathrm{~mm}$ using a 10\% oxalic acid solution followed by OP- FELT $200 \mathrm{~mm}$ with OPS solution (Colloidal Silica 0.04 microns).

The bone-shaped plate specimens of $75 \mathrm{~mm}$ length with test area dimensions of $33 \times 6 \times 0.9 \mathrm{~mm}$ (length $\mathrm{x}$ width $\mathrm{x}$ thickness) were prepared according to ASTM E8-15 ${ }^{13}$ for tensile tests at room temperature on an EMIC $100 \mathrm{kN}$ mechanical test system at a strain rate of $10^{-5} \mathrm{~s}^{-1}$ for the unhydrided and hydrided conditions. Fracture surfaces of the specimens were observed with a JEOL JSM 6460 scanning electron microscope under $20 \mathrm{kV}$.

\section{Results and Discussion}

Most developments of zirconium alloys for PWR reactors aims to obtain an $\alpha$-Zr matrix with dispersed $\beta-\mathrm{Nb}$ precipitates. To achieve this, heat treatment after the mechanical processing is required. This treatment can lead to a partially or a fully recrystallized microstructure. The time and temperature of the heat treatment performed in this work were based on a study by Tian et. al. ${ }^{8}$ on the recrystallization behavior of a $\mathrm{Zr}-1 \mathrm{Nb}$ alloy subjected to different deformations at several annealing temperatures, where full recrystallization was achieved at $600^{\circ} \mathrm{C}$ after 15 minutes for a $50 \%$ deformed and 84 minutes for $30 \%$ deformed $\mathrm{Zr}-1 \mathrm{Nb}$ alloy, resulting in a hcp $\mathrm{Zr}$ matrix (grain size about $4 \mu \mathrm{m}$ ) with small $\beta-\mathrm{Nb}$ precipitates. Recrystallization levels of the cold rolled and annealed samples were evaluated by micro hardness measurements, which are presented in Table 1.

Table 1. Vickers microhardness of cold rolled and annealed alloys.

\begin{tabular}{ccc}
\hline Alloy & Condition & Vickers microhardness $(\mathbf{H V})$ \\
\hline $\mathrm{Zr}-1 \mathrm{Nb}$ & cold rolled & $302 \pm 6$ \\
$\mathrm{Zr}-1 \mathrm{Nb}$ & annealed & $260 \pm 18$ \\
$\mathrm{Zr}-1 \mathrm{Nb}-1 \mathrm{Sn}-0.1 \mathrm{Fe}$ & cold rolled & $287 \pm 10$ \\
$\mathrm{Zr}-1 \mathrm{Nb}-1 \mathrm{Sn}-0.1 \mathrm{Fe}$ & annealed & $249 \pm 5$ \\
\hline
\end{tabular}

The results show a decrease in hardness for annealed conditions for both compositions, indicating a full recrystallization of the microstructure, as reported in literature ${ }^{8,14}$. According to literature ${ }^{15}$, the heat treatment allowed concomitant process of aging, where precipitates are formed and grow, and recrystallization as was observed in other Zr-based alloys. Comparing the results for both alloys, the absolute hardness reduction for $\mathrm{Zr}-1 \mathrm{Nb}-1 \mathrm{Sn}-0.1 \mathrm{Fe}$ alloy were lower than $\mathrm{Zr}-1 \mathrm{Nb}$ due to the fact that $\mathrm{Nb}$ tends to precipitate and the others alloying additions stay in solid solution in Zr matrix, delaying recrystallization during annealing ${ }^{16}$. Considering the 
percentage reduction of hardness, the two alloys presented similar results ( $13 \%$ approximately), indicating that both of them underwent the same degree of softening.

Figure 2 shows the diffraction pattern of $\mathrm{Zr}-1 \mathrm{Nb}$ and $\mathrm{Zr}-1 \mathrm{Nb}-1 \mathrm{Sn}-0.1 \mathrm{Fe}$ alloys. The XRD analyses indicate that both alloys have an $\alpha$-Zr matrix. The $\beta$-phase precipitates could not be observed by XRD due to its low volume fraction.

Hydrogen absorption kinetics of the annealed samples are shown in Figure 3. The kinetic curves show that both hydrogen absorption times are quite different. The alloys absorbed almost the same hydrogen quantity, $0.42 \mathrm{wt} \% \%$ for $\mathrm{Zr}-1 \mathrm{Nb}-1 \mathrm{Sn}-0.1 \mathrm{Fe}$ and $0.39 \mathrm{wt} . \%$ for $\mathrm{Zr}-1 \mathrm{Nb}$. Regarding the time for the beginning of the process, hydrogen absorption in $\mathrm{Zr}-1 \mathrm{Nb}-1 \mathrm{Sn}-0.1 \mathrm{Fe}$ only started after $11 \mathrm{~h}$, reaching the maximum after 21 hours. In contrast, $\mathrm{Zr}-1 \mathrm{Nb}$ began absorption almost immediately; however, it presented a slow kinetics with only $0.3 \%$ of hydrogen absorbed after 21 hours and a maximum reached after 38 hours.

Both alloys presented similar values for the amount of hydrogen absorbed. Considering that they gone through the same thermomechanical process that lead to the same degree

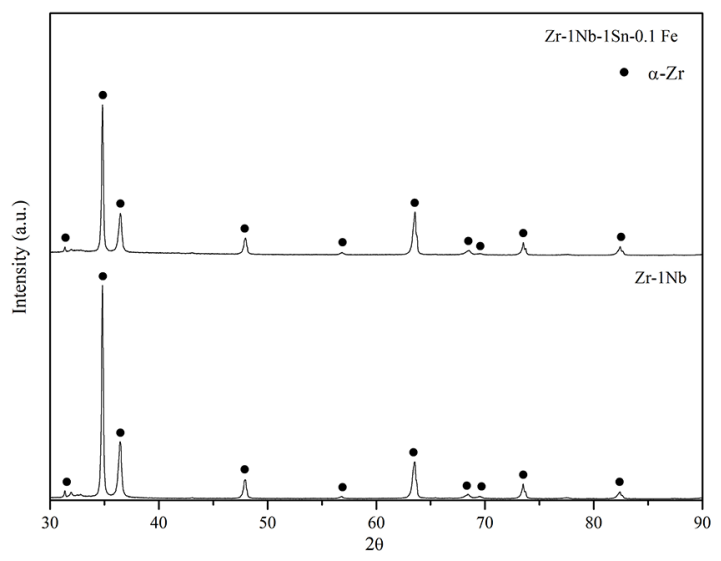

Figure 2. XRD pattern of the $\mathrm{Zr}-1 \mathrm{Nb}$ and $\mathrm{Zr}-1 \mathrm{Nb}-1 \mathrm{Sn}-0.1 \mathrm{Fe}$ alloys after the thermomechanical process

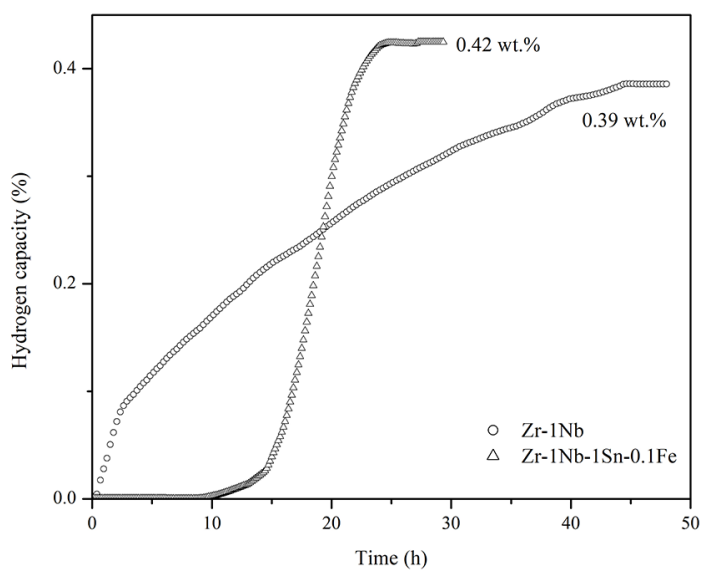

Figure 3. Absorption kinetics curves of heat treated $\mathrm{Zr}-1 \mathrm{Nb}$ and $\mathrm{Zr}-1 \mathrm{Nb}-1 \mathrm{Sn}-0.1 \mathrm{Fe}$ alloys obtained at $320^{\circ} \mathrm{C}$ under 10 bar of hydrogen of softening, and the proposed heat treatment was capable to induce recrystallization ${ }^{8}$, it is possible to predict that the final microstructure has an $\alpha-\mathrm{Zr}$ matrix with recrystallized grains with $\beta-\mathrm{Nb}$ precipitates. Based on this, the slightly higher value of hydrogen absorption in $\mathrm{Zr}-1 \mathrm{Nb}-1 \mathrm{Sn}-0.1 \mathrm{Fe}$ could be associated with the alloying additions, specially $\mathrm{Sn}$, that stabilizes $\alpha-\mathrm{Zr}$ and promotes an increase of terminal solid solubility (TSS), by increasing the entropy of mixing ${ }^{16}$.

Regarding the absorption kinetics, $\mathrm{Zr}-1 \mathrm{Nb}-1 \mathrm{Sn}-0.1 \mathrm{Fe}$ has a faster hydrogen absorption compared to $\mathrm{Zr}-1 \mathrm{Nb}$. This behavior was previously reported by Silva et. al. ${ }^{17}$ studying hydrogen gas permeation in the same alloys. According to Silva et. al. ${ }^{17}$, hydrogen diffusivity was very slow in $\mathrm{Zr}-1 \mathrm{Nb}$ due to the formation of a hydride front, which has a low growth rate and reduces the mechanism of hydrogen absorption. In $\mathrm{Zr}-1 \mathrm{Nb}-1 \mathrm{Sn}-0.1 \mathrm{Fe}$ alloy, the presence of second particles rich in $\mathrm{Fe}$ and $\mathrm{Nb}$, may reduces $\mathrm{Nb}$ efficiency in reduce hydrogen diffusion, increasing hydrogen kinetics. Ribeiro et al. ${ }^{18}$ studied $\mathrm{Zr}-\mathrm{Nb}$ based alloys with different alloying additions ( $\mathrm{Al}, \mathrm{Cu}$ and $\mathrm{Mn})$ in as-rolled and recrystallized conditions. The $\mathrm{Al}$ addition, which is a $\alpha$-stabilizer as $\mathrm{Sn}$, leads to a fast absorption after an incubation time while the other elements presented a slower absorption.

Besides microstructure differences, the results of the absorption obtained in the present work and in literature ${ }^{18}$ can be explained by the type and amount of alloying elements and the microstructural characteristics such as grain size, volume fraction and particle size of the second phase.

The onset time to absorption in $\mathrm{Zr}-1 \mathrm{Nb}-1 \mathrm{Sn}-0.1 \mathrm{Fe}$ alloy could be, at first, associated to an oxide film formation in the samples surface during prior heating, but no oxide layer was observed on OM. This delay for the beginning of hydrogen absorption had already been reported by Ribeiro et. al. ${ }^{18}$ and Dupim et al. ${ }^{19}$ This behavior could be attributed not only to the presence of elements in solid solution, that delays hydrogen absorption, but also the combined effect of microstructure and alloying elements, that lead to a longer onset time. On the other hand, $\mathrm{Zr}-1 \mathrm{Nb}$ alloy started absorption instantaneously, however its kinetic was very slow, resulting in a lower overall absorption.

Although absorption kinetics do not allow inferences on hydrogen diffusion itself, since it is not possible to separate the portion corresponding to the diffusion and hydride formation, this test is of great importance in evaluating the materials performance in degrading environments.

Hydride distribution and orientation in the transverse section of the plate can be seen in Figure 4. For both alloys, hydrides are uniformly distributed and partially aligned to the rolling plane in zirconium spacing matrix. This behavior is strongly dependent on crystallographic texture developed in thermomechanical process ${ }^{20}$. When the basal plane is parallel to the surface, the hydride plates will preferably be formed in this orientation, avoiding the precipitation along the thickness direction ${ }^{21}$. Oh et. al. ${ }^{16}$ studied the influence of 

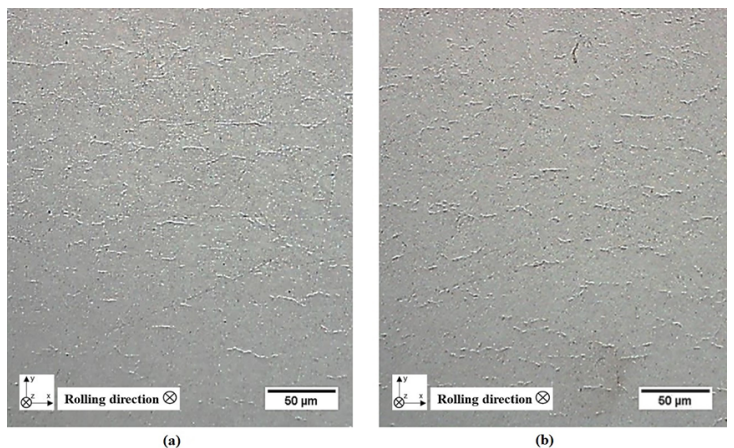

Figure 4. Transversal section of plates after gas hydrogenation at $320^{\circ} \mathrm{C}$ for $48 \mathrm{~h}$ showing hydride formation. (a) $\mathrm{Zr}-1 \mathrm{Nb}$ and (b) $\mathrm{Zr}-1 \mathrm{Nb}-1 \mathrm{Sn}-0.1 \mathrm{Fe}$

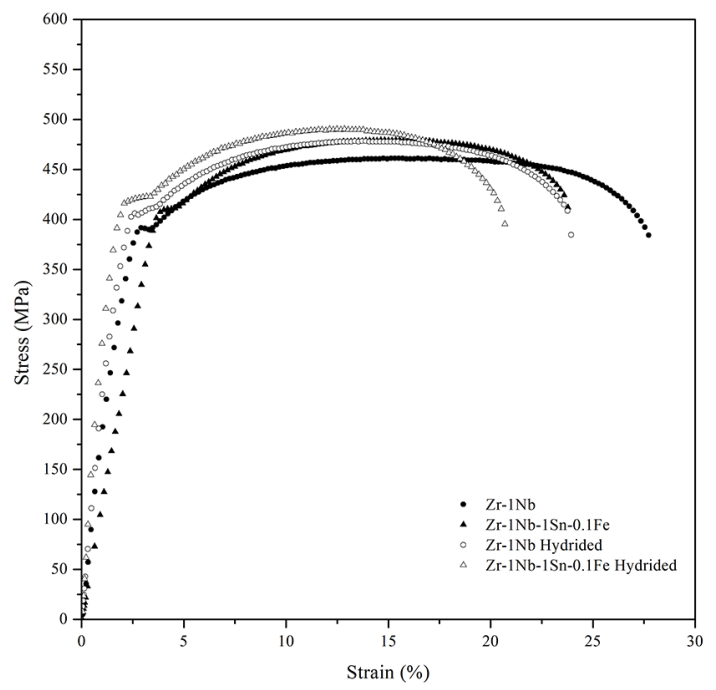

Figure 5. Stress-strain curves for $\mathrm{Zr}-1 \mathrm{Nb}$ and $\mathrm{Zr}-1 \mathrm{Nb}-1 \mathrm{Sn}-0.1 \mathrm{Fe}$ for thermomechanically processed specimens after hydrogenation at $320^{\circ} \mathrm{C}$ for $48 \mathrm{~h}$.

$\mathrm{Sn}$ and $\mathrm{Nb}$ addition on hydride formation and observed that Sn additions tend to increase the length and inter-hydride spacing when compared to $\mathrm{Zr}-1 \mathrm{Nb}$. As the element alloying additions in the alloys investigated in this work are very small, about 1wt.\%, great differences in these characteristics, as confirmed by $\mathrm{Oh}$ et. al. study ${ }^{16}$ could not be observed.

Engineering stress-strain curves for $\mathrm{Zr}-1 \mathrm{Nb}$ and $\mathrm{Zr}$ $1 \mathrm{Nb}-1 \mathrm{Sn}-0.1 \mathrm{Fe}$ in the thermomechanically processed and hydrogenated at $320^{\circ} \mathrm{C}$ for $48 \mathrm{~h}$ conditions are shown in Figure 5. Comparing the results between the thermomechanically
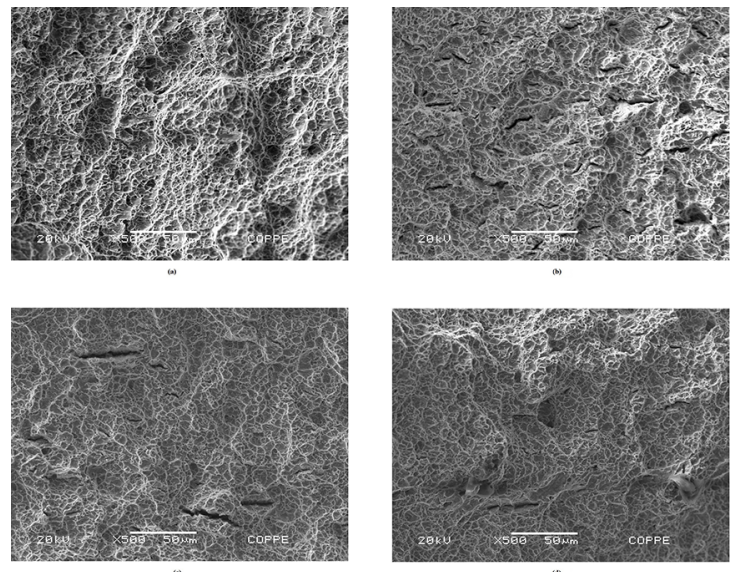

Figure 6. SEM fractographs after tensile tests at room temperature of: (a) unhydrided $\mathrm{Zr}-1 \mathrm{Nb}$; (b) unhydrided $\mathrm{Zr}-1 \mathrm{Nb}-1 \mathrm{Sn}-0.1 \mathrm{Fe}$; (c) hydrided $\mathrm{Zr}-1 \mathrm{Nb}$ and (d) hydrided $\mathrm{Zr}-1 \mathrm{Nb}-1 \mathrm{Sn}-0.1 \mathrm{Fe}$ - cracks are indicated by arrows

processed alloys, it could be clearly seen that both groups exhibit similar mechanical properties. The yield strength, ultimate tensile strength and elongations before and after hydrogenation for both alloys are shown in Table 2 . The slightly higher yield strength and ultimate tensile strength values of $\mathrm{Zr}-1 \mathrm{Nb}-1 \mathrm{Sn}-0.1 \mathrm{Fe}$ can be associated to the presence of the other alloying elements as $\mathrm{Sn}$, which is more effective in strengthening than $\mathrm{Nb}$ additions in $\mathrm{Zr}$ alloys ${ }^{16}$.

After hydrogenation, a slight increase in strength with corresponding decrease in ductility were observed for both alloys. This reduction can be associated with the absorbed hydrogen and the presence of hydride which have a stronger effect on ductility loss than on tensile strength in $\mathrm{Zr}$ alloys, possibly severely degrading the ductility of these materials ${ }^{16,22}$. Another characteristic that represents the effect of hydride presence is that upper and lower yield points observed on the unhydrided specimens almost disappeared, indicating that the existence of the hydrides can suppress the yield point phenomenon as observed by Tung et al. ${ }^{22}$.

The mechanical properties results showed that both alloys, despite the chemical composition, are resistant to hydrogen when the absorbed concentration is small, of the order of $0.4 \mathrm{wt} . \% \mathrm{H}$. Therefore, even if hydrides are formed in the sample, the ductility loss is very low. This result corroborates to the one observed by da Silva et al. ${ }^{17}$ in the analysis of commercial alloys with the same compositions as those one tested in the present work.

Table 2. Tensile test results for $\mathrm{Zr}-1 \mathrm{Nb}$ and $\mathrm{Zr}-1 \mathrm{Nb}-1 \mathrm{Sn}-0.1 \mathrm{Fe}$ before and after hydrogenation.

\begin{tabular}{ccccc}
\hline Alloy & Condition & Yield strength (MPa) & Ultimate tensile strength (MPa) & Elongation (\%) \\
\hline $\mathrm{Zr}-1 \mathrm{Nb}$ & Unhydrided & $388 \pm 3$ & $458 \pm 4$ & $27 \pm 2$ \\
$\mathrm{Zr}-1 \mathrm{Nb}$ & Hydrided & $403 \pm 9$ & $479 \pm 2$ & $24 \pm 4$ \\
$\mathrm{Zr}-1 \mathrm{Nb}-1 \mathrm{Sn}-0.1 \mathrm{Fe}$ & Unhydrided & $406 \pm 6$ & $479 \pm 1$ & $22 \pm 1$ \\
$\mathrm{Zr}-1 \mathrm{Nb}-1 \mathrm{Sn}-0.1 \mathrm{Fe}$ & Hydrided & $405 \pm 23$ & $479 \pm 17$ & $19 \pm 0$ \\
\hline
\end{tabular}


Figure 6(a) and (b) shows SEM fractographs of the unhydrided specimens. Both alloys exhibited ductile fracture surface by microvoid coalescence. Secondary cracks were observed in $\mathrm{Zr}-1 \mathrm{Nb}-1 \mathrm{Sn}-0,1 \mathrm{Fe}$. For the charged specimens, Figures 6(c) and (d), the ductile fracture features are prevalent for both alloys and it is noteworthy that the micrographs also display the presence of secondary cracks with quasi-cleavage aspect. Comparing the results of $\mathrm{Zr}-1 \mathrm{Nb}-1 \mathrm{Sn}-0.1 \mathrm{Fe}$, it is noted that the length and the amount of secondary cracks, as shown in Figure 6(b) are higher than those in Figure 6(d). These micrographs suggest that a crack could propagate through interface between the hydride and matrix, reducing ductility, in accordance with tensile tests results. The embrittlement effect of hydrogen on the mechanical properties of zirconium alloys was observed by Tung et al. ${ }^{22}$ when studying the effect of the hydrogen content in Zyrcaloy-4. Elongation was reduced after hydriding and secondary cracks were also observed in fractographic analysis.

The ductile-brittle fracture aspect may be associated with the presence of the hydrides, that induce a significant localized resistance loss, leading to the formation of a brittle region, while in hydride-free regions, the fracture remains ductile. Only a higher concentration of hydrides would be sufficient to cause a significant loss of strength and ductility.

\section{Conclusions}

The alloys were synthetized by arc melting and thermomechanical processing, resulting in a recrystallized microstructure. Hydrogen absorption kinetics indicate that $\mathrm{Zr}-1 \mathrm{Nb}-1 \mathrm{Sn}-0.1 \mathrm{Fe}$ has a slightly higher amount of absorbed hydrogen when compared to $\mathrm{Zr}-1 \mathrm{Nb}$. This behavior could be associated to the TSS increase induced by the presence of alloying elements as Sn. Related to the onset time of absorption, in the $\mathrm{Zr}-1 \mathrm{Nb}$ alloy it initiates almost immediately whereas in the $\mathrm{Zr}-1 \mathrm{Nb}-1 \mathrm{Sn}-0.1 \mathrm{Fe}$ alloy it takes $11 \mathrm{~h}$ to initiate. Hydrides were uniformly distributed and partially aligned in zirconium matrix and this condition is dependent on heat treatment and crystallographic texture. Tensile tests and fractographic analyses indicates that, even with localized ductility loss caused by hydride formation, both alloys are still resistant to hydride embrittlement.

\section{Acknowledgements}

The authors acknowledge the financial support of FINEP, CNPq, CAPES and FAPERJ.

\section{References}

1. Samal MK, Sanyal G, Chakravartty JK. Investigation of failure behavior of two different types of Zircaloy clad tubes as nuclear reactor pins. Engineering Failure Analysis. 2011;18(8):2042-2053.
2. Keys LH, Johanson G, Malin AS. The physical metallurgy of high strength zirconium alloys. Journal of Nuclear Materials. 1976;59(2):137-148.

3. Zielinski A, Sobieszczyk S. Hydrogen-enhanced degradation and oxide effects in zirconium alloys for nuclear applications. International Journal of Hydrogen Energy. 2011;36(14):86198629 .

4. Tewari R, Srivastava D, Dey GK, Chakravarty JK, Banerjee S. Microstructural evolution in zirconium based alloys. Journal of Nuclear Materials. 2008;383(1-2):153-171.

5. Saibaba N. Fabrication of seamless calandria tubes by cold pilgering route using 3-pass and 2-pass schedules. Journal of Nuclear Materials. 2008;383(1-2):63-70.

6. Bickel GA, Griffiths M. Manufacturing variability and deformation for $\mathrm{Zr}-2.5 \mathrm{Nb}$ pressure tubes. Journal of Nuclear Materials. 2008;383(1-2):9-13.

7. Murgatroyd RA, Rogerson A. An assessment of the influence of microstructure and test conditions on the irradiation growth phenomenon in zirconium alloys. Journal of Nuclear Materials. 1980;90(1-3):240-248.

8. Tian H, Wang X, Gong W, Zhou J, Zhang H. Recrystallization behavior of cold-rolled Zr-1Nb alloy. Journal of Nuclear Materials. 2015;456:321-328.

9. Daunys M, Dundulis R, Grybenas A, Krasauskas P. Hydrogen influence on mechanical and fracture mechanics characteristics of zirconium $\mathrm{Zr}-2.5 \mathrm{Nb}$ alloy at ambient and elevated temperatures. Nuclear Engineering and Design. 2008;238(10):2536-2545.

10. Min SJ, Kim MS, Kim KT. Cooling rate and hydrogen content dependent hydride reorientation and mechanical property degradation on $\mathrm{Zr}-\mathrm{Nb}$ alloy claddings. Journal of Nuclear Materials. 2013;441(1-3):306-314.

11. Conić D, Gradišek A, Radaković J, Irdoc M, Mirkovic M, Čebela $\mathrm{M}$, et al. Influence of $\mathrm{Ta}$ and $\mathrm{Nb}$ on the hydrogen absorption kinetics in Zr-based alloys. International Journal of Hydrogen Energy. 2015;40(16):5677-5682.

12. Ivanova SV. Effect of hydrogen on serviceability of zirconium items in VVER and RBMK-type reactors fuel assemblies. International Journal of Hydrogen Energy. 2002;27(7-8):819824.

13. ASTM International. ASTM E8/E8M-15a - Standard Test Methods for Tension Testing of Metallic Materials. West Conshohocken: ASTM International; 2015.

14. Li MH, Ma M, Liu WC, Yang FQ. Recrystallization behavior of cold-rolled Zr 702. Journal of Nuclear Materials. 2013;433(13):6-9.

15. Jung YI, Lee MH, Kim HG, Park JY, Jeong YH. Behavior of a recrystallization in HANA-4 and HANA-6 zirconium-based alloys. Journal of Alloys and Compounds. 2009;479(1-2):423426.

16. Oh SJ, Jang C, Kim JH, Jeong YH. Microstructure and hydride embrittlement of zirconium model alloys containing niobium and tin. Materials Science and Engineering: A. 2011;528(1011):3771-3776. 
17. Silva KRF, dos Santos DS, Ribeiro AF, Almeida LH. Hydrogen Diffusivity and Hydride Formation in Rich-Zirconium Alloys Used in Nuclear Reactors. Defect and Diffusion Forum. 2010;297-301:722-727.

18. Ribeiro RM, Woyames CB, de Almeida LH, dos Santos DS. Effect of microstructure and addition of alloying elements on hydriding kinetics of $\mathrm{Zr}-\mathrm{Nb}$-based alloys. International Journal of Hydrogen Energy. 2015;40(47):17118-17127.

19. Dupim IS, Moreira JML, Huot J, Santos SF. Effect of cold rolling on the hydrogen absorption and desorption kinetics of Zircaloy-4. Materials Chemistry and Physics. 2015;155:241245.
20. Vaibhaw K, Rao SVR, Jha SK, Saibaba N, Jayaraj RN. Texture and hydride orientation relationship of Zircaloy-4 fuel clad tube during its fabrication for pressurized heavy water reactors. Journal of Nuclear Materials. 2008;383(1-2):71-77.

21. Qin W, Kiran Kumar NAP, Szpunar JA, Kozinski J. Intergranular d-hydride nucleation and orientation in zirconium alloys. Acta Materialia. 2011;59(18):7010-7021.

22. Tung HM, Chen TC, Tseng CC. Effects of hydrogen contents on the mechanical properties of Zircaloy-4 sheets. Materials Science and Engineering: A. 2016;659:172-178. 